\title{
Dignidad y autonomía. Reflexiones sobre la tradición kantiana*
}

\author{
Dignity and autonomy. Reflections about Kantian tradition
}

\author{
Por: Thomas Gutmann \\ Universität Münster \\ Münster, Alemania \\ E-mail: t.gutmann@uni-muenster.de \\ Trad.: Carlos Emel Rendón \\ Universidad Nacional de Colombia \\ Medellín, Colombia \\ E-mail: crendona@unal.edu.co
}

Fecha de recepción: 22 de noviembre 2017

Fecha de aprobación: 14 de agosto de 2018

Doi: 10.17533/udea.ef.n59a11

Resumen. La idea kantiana según la cual sólo las personas pueden pretender respeto ("dignidad") y sólo frente a ellas pueden existir derechos morales, aunque, al mismo tiempo, no todos los seres humanos son personas en este sentido prescriptivo estricto, contiene un considerable potencial de exclusión. El presente artículo reconstruye bajo este aspecto la arquitectura de la filosofía moral de Kant (y de la tradición kantiana) e investiga el alcance y los límites de las diferentes propuestas de solución inmanentes a su teoría.

Palabras claves: Kant, dignidad, autonomía, derechos morales, personas

Abstract. Kantian idea according to which only people can claim respect ("dignity") and only for them can moral rights exist, yet, at the same time, not all human beings are people in this strict prescriptive sense, contains considerable potential of exclusion. From this view, the present article reconstructs the architecture of Kant's moral philosophy (and of the Kantian tradition) and investigates the scope and the limits of the different proposals of solution based on his theory.

Keywords: Kant, dignity, autonomy, moral rights, persons

* Este texto apareció originalmente publicado en alemán en: Gutmann, T. (2010). Würde und Autonomie. Überlegungen zur Kantischen Tradition. Jahrbuch für Wissenschaft und Ethik, 15(1), 3-34. doi:10.1515/9783110222906.3. El texto fue traducido y reproducido con autorización del autor.

Cómo citar este artículo:

MLA: Gutmann, Thomas. "Dignidad y autonomía. Reflexiones sobre la tradición kantiana". Traducido por Carlos Emel Rendón, Estudios de Filosofia 59 (2019): 233-254.

APA: Gutmann, T. (2019). Dignidad y autonomía. Reflexiones sobre la tradición kantiana (Carlos Emel Rendón, Trad.). Estudios de Filosofia, 59, 233-254.

Chigado: Gutmann, T. "Dignidad y autonomía. Reflexiones sobre la tradición kantiana". Traducido por Carlos Emel Rendón. Estudios de Filosofía no 59 (2019): 233-254. 


\section{Personalidad y dignidad ${ }^{1}$}

El concepto de persona ${ }^{2}$ puede ser usado en forma descriptiva y prescriptiva. Como concepto prescriptivo sirve, sobre todo en la filosofía del derecho, para la caracterización de seres a los que se les adjudican derechos subjetivos, entre ellos uno fundamental: las personas tienen el derecho al respeto, y puesto que a todas las personas les corresponde este estatus en igual medida, las personas tienen derecho a igual respeto. Como personas jurídicas tienen derecho a ser respetadas como personas en el derecho y mediante el derecho, incluso la idea del estado liberal de derecho puede reformularse con la frase de que tenemos un derecho recíproco a "equal concern and respect" (Dworkin, 1984, p. 298; Dworkin 1985, p. 191), es decir, a igual respeto. En el ordenamiento jurídico de la República Federal de Alemania este precepto del respeto tiene su expresión en al art.1, parágrafo 1 de la Ley Fundamental 1 (Grundgesetz) (GG), que declara inviolable la dignidad del hombre. En la filosofía moral, el principio del respeto a personas opera como suposición fundamental de planteamientos no consecuencialistas, para los cuales de lo que se trata en principio es de expresar que el individuo es fin en sí mismo.

El vínculo entre personalidad y dignidad, es decir, el principio del respeto a las personas, se remonta en esta forma, en lo esencial, a Immanuel Kant, y se alimenta todavía en forma predominante de un pensamiento que, dejando de lado todas las diferenciaciones, puede caracterizarse como 'la tradición kantiana'. El presente trabajo, que se inscribe a sí mismo en esta tradición, pretende iluminar un lado oscuro de este nexo de la recepción. Su interés se centra en el considerable potencial de exclusión del concepto kantiano de dignidad, según el cual, sólo las personas tienen derecho al respeto y sólo ante ellas pueden existir deberes morales, al tiempo, que, sin embargo, no todos los seres humanos son personas en este sentido prescriptivo estricto (secciones 2 a 5). Se preguntará, por tanto, (sección 6) cómo puede habérselas el derecho con el resultado de que el modelo originario de su concepto central no procede de manera suficientemente incluyente.

\footnotetext{
1 El texto se basa en la conferencia dada por el autor para la habilitación en la Facultad de Filosofía, Teoría de la ciencia y Estudios teológicos de la Universidad Ludwig Maximilian de München. El autor agradece particularmente a Daniela Baur, Otto Fuchs y al Dr. Bernhard Jakl por las valiosas indicaciones.

2 Para una visión panorámica: Quante (2007), Sturma (2001).
} 


\section{Sobre los conceptos de persona y dignidad en Kant}

Una mirada a los textos básicos de filosofía moral de Kant, la Fundamentación de la metafisica de las costumbres de 1785 y la Crítica de la razón práctica, aparecida tres años después (1788), confirma que para Kant no todos los seres humanos son personas y poseen, como tales, derecho al respeto.

En la Fundamentación, Kant resume la ley fundamental de la razón pura práctica, el imperativo categórico, como se sabe, en las palabras: "Actúa sólo según aquellas máximas por cuyo medio puedas querer al mismo tiempo, que se conviertan en una ley universal" [Kant, 1996 (1785)]. En la llamada fórmula del fin, que reformula su ética deontológica en conceptos materiales, da al imperativo una segunda versión (de tres a seis, según la enumeración): "Obra de tal manera, que puedas usar la humanidad, tanto en tu persona como en la persona de todo otro, siempre al mismo tiempo como fin, nunca meramente como medio" [Kant, 1996 (1785), p. 189].

Desde un punto de vista exegético puede resultar aconsejable seguir la propia indicación de Kant de que el imperativo categórico, en el fondo, es "sólo uno" [Kant, 1996 (1785), p. 173], de que esta "fórmula del fin" (a pesar de su fundamentación aparentemente teleológica, incluso ético-axiológica) representa una expresión, de contenido equivalente, de las otras fórmulas del imperativo categórico ( $c f$. Horn, 2004, p. 196; O’Neill, 1989; Habermas, 2005, p. 98) y que aclara, además, la "materia" [Kant, 1996 (1785), p. 162] del imperativo categórico. Aunque se quisiera negar que la idea (entendible en el sentido de un realismo moral) ${ }^{3}$ según la cual seres racionales y, por tanto, capaces de autonomía y establecer fines, tienen un valor absoluto sea "la tesis central en la ética de Kant" (Schnöcker, 2007, p. 142; Wood, 2008, p. 94), la fórmula de la humanidad en nosotros como fin en sí misma es, en todo caso, para el argumento que aquí perseguimos, de importancia particular: en primer lugar, porque, para su deducción, Kant desarrolla su teoría del estatus moral, esto es, su respuesta a la pregunta por qué propiedad debe tener un ser para que sea "objeto del respeto" [Kant, 1996 (1785), p. 187] y puedan existir respecto de él deberes morales. En segundo lugar, la fórmula del fin es relevante en la medida en que la prohibición en ella expresada de la instrumentalización de las

3 Contra el constructivismo de Korsgaard ( $c f$. Korsgaard, 2005, p. 92; Wood 2008, p. 92; Timmermann, 2006; 2008). Kant subraya el carácter de la finalidad en sí mismo como elemento necesario de la autocomprensión de seres racionales. Véase: Kant (1996 [1785], p. 188). 
personas descansa argumentativamente en el trasfondo de la doctrina kantiana de la virtud y la filosofía del derecho de la Metafísica de las Costumbres de 1797; y es importante, finalmente, porque representa el modelo originario del principio del respeto a las personas, el cual constituye el núcleo del pensamiento central común a las actuales variantes kantianas de la filosofía moral y del derecho.

Para la fundamentación de la fórmula del fin Kant argumenta (en principio sólo como postulado) que "el hombre, y todo ser racional en general, [...]" existe "como fin en sí mismo", que tiene, por tanto, "una dignidad, es decir, un valor incondicionado e incomparable" y puede por ello pretender "respeto" [Kant, 2012 a (1797), pp. 334-335]. . Que con los conceptos "hombre" y "humanidad" no se refiere Kant en estos pasajes a los seres pertenecientes al género homo sapiens, se sigue del hecho de que pretende obtener los fundamentos de la filosofía moral del concepto de la razón pura práctica sin recurso alguno a los supuestos antropológicos. El principio moral fundamentado de esta manera tiene por ello que exigir validez "a todos los seres racionales" y sólo por ello y en esa medida puede "ser una ley para la voluntad humana” [Kant, 2012 (1797), p. 181]. Por ello, la clase de los seres racionales (capaces de acción) no es idéntica a la especie biológica hombre. De una parte, seres racionales no-humanos, son imaginables, para Kant, "en otros planetas" [Kant, 2012 (1797), p. 246] ${ }^{5}$ y, de otra, no todos los hombres son seres racionales y por tanto personas caracterizadas con el atributo "dignidad". No la naturaleza del hombre, sino la "naturaleza racional existe como fin en sí mismo", sólo "los seres racionales se denominan personas" [Kant, 2012 (1797), p. 187]. El estatus "persona" supone la imputabilidad de sus acciones y con ello la capacidad existente en acto para la autodeterminación según principios morales y (jurídicos) [Kant, 2012 (1797), p. 30]. Kant aclara por ello en la Fundamentación que "moralidad" - es decir, nuestra capacidad de determinar la propia voluntad según leyes morales - es "la condición únicamente bajo la cual un ser racional puede ser fin en sí mismo": "la moralidad y la humanidad, en tanto que ésta es capaz de la misma, es lo único que tiene dignidad” [Kant, 2012 (1797), p. 201]. La dignidad moral descansa en la capacidad de autodeterminación práctica según normas racionales. Por esta razón, Kant puede utilizar el respeto a la "humanidad" como sinónimo de respeto por la ley moral [Kant, 2012 (1797), p. 133] o por la libertad moral del hombre; sin

$4 C f$. Kant (1996 [1785], pp. 187, 130). Acerca del respeto como "conciencia de la coerción inmediata sobre la voluntad por la ley": Kant (2005 [1788], p. 140). También véase: Walker (1989).

5 Véase también: “demonios (siempre que tengan entendimiento)” en: Kant (2002 [1795], p. 74). 
embargo, el "verdadero objeto del respeto" es, según Kant, la voluntad individual en su capacidad de darse fines racionales (y determinarse, a la postre, moralmente, es decir, conforme al imperativo categórico). En otras palabras: "Autonomía es [...] el fundamento de la dignidad de la naturaleza humana y de toda naturaleza racional" [Kant, 2012 (1797), p. 203]. Intrínsecamente valioso es el hombre singular, concreto, fenoménico, en virtud de su participación en lo nouménico, es decir, si y en tanto que se distingue por la capacidad de obrar libre y racionalmente (Horn, 2004, p. 206; O’Neill, 1989, p. 135; Wood, 2008, p. 94; Geismann, 2004, p. 467 ; $c f$. Cohen, 1877, p. 241). El concepto del rational agency tiene sus buenas razones para estar en el centro de la actual recepción anglosajona de Kant. ${ }^{6}$ Este nexo, desarrollado sistemáticamente en la Fundamentación de la metafisica de las costumbres, permanece sin modificación en Crítica de la razón práctica. El hombre "y con él toda criatura racional es fin en sí mismo", porque y en tanto que él es "el sujeto de la ley moral" [Kant, 2005 (1788), p. 104]; la posibilidad "de estar determinado inmediatamente a la acción por una ley pura de la razón" identifica a los seres como personas [Kant, 2005 (1788), p. 140]. Finalmente, en La Metafísica de las costumbres, Kant parafrasea esta idea con las siguientes palabras:

\footnotetext{
En el sistema de la naturaleza el hombre [...] es un ser de escasa importancia [...]. Ahora bien, el hombre, considerado como persona, es decir, como sujeto de una razón prácticomoral, está situado por encima de todo precio; porque como tal [...] puede valorarse [...] como fin en sí mismo, es decir, posee una dignidad (un valor interno absoluto), gracias a la cual infunde respeto hacia él a todos los demás seres racionales del mundo [Kant, 2012 (1797), pp. 298-299].
}

Así pues, cuando Kant, en el marco de la fundamentación de su filosofía moral habla de la "humanidad", a la que debemos tributar respeto y a la que debemos usar "tanto en nuestra persona como en la persona de todo otro, siempre como fin [y] nunca meramente como medio", no se refiere a la especie biológica u otra representación extensiva, sino que utiliza el concepto como un "supraconcepto" (O'Neill, 1989, p.137) para un conjunto de capacidades y propiedades normativas, fundamentales de la persona, es decir, de aquella "idea de la humanidad" [Kant, 1996 (1785), p. 189], que consiste en el lado inteligible o nouménico del hombre, en su capacidad para la causalidad por libertad, es decir, para darse fines, y finalmente, en la capacidad para la autodeterminación según máximas universalisables que se da a sí mismo. En este concepto no se oculta teleología aristotélica alguna. Kant, por el contrario, concibe los fines de las acciones de los seres racionales como

6 Por ejemplo en: O’Neill (1975; 1989), Herman (1993), Korsgaard (1996); cf. Horn (2004, p. 207). 
independientes de toda teleología natural y precisamente por ello como libres. ${ }^{7}$ Al mismo tiempo, en el marco del completo distanciamiento de la filosofía práctica kantiana de Aristóteles, no pueden obtenerse criterios de la naturaleza del género para el obrar. El motivo para el imperativo categórico no reside en una disposición empírica particular de la especie humana y, a la inversa, tampoco la sola pertenencia a ésta puede ser suficiente para la mera atribución del estatus de "persona" en el marco del planteamiento kantiano. ${ }^{8}$ La tesis contraria de que en Kant "la humanidad como género" debe "ser objeto de respeto" en el sentido de que "todo individuo del género [...]" tiene "derecho al respeto" por el hecho de que tiene parte en la humanidad como homo noumenon (Ricken, 1989, p. 239), descansa en meras equivocaciones e induce por ello a error. Kant no opera con una metafísica aristotélica de la sustancia humana, en la que participaran sin más también aquellos miembros de la especie humana que carecen de ella por accidente. No hay en Kant entelequia alguna de la persona. Su nueva construcción filosófica-moral, concebida en términos de una teoría de la acción, del concepto de persona se libera, precisamente, de semejante ontología de la sustancia. Por ello, la concepción según la cual Kant confiere dignidad y estatus de persona al hombre como ser genérico, esto es, a todos los hombres (incluyendo el pre-embrión), resulta tan poco sostenible como la tesis de que un concepto de la "unidad de la persona" garantizaría también para Kant un estatus unitario normativo de la vida humana del embrión, independientemente de su capacidad real de obrar racional y responsablemente. En lugar de ello, "la humanidad", entendida como la capacidad de autodeterminación racional según el principio de la personificación que subyace a la fórmula kantiana del fin, debe respetarse sólo en la persona concreta que la encarna realmente. No hay en Kant una "dignidad humana universal en cuyo marco una "disposición" no realizada a la autodeterminación exigiera derecho al respeto, en el sentido estricto del término. Sólo las personas pueden pretender consideración moral ( $c f$. Pogge, 1989, p. 182); por eso, sobre la base del principio kantiano sólo puede haber deberes morales respecto de personas concretas, es decir, dadas como objeto de la experiencia [Kant, 2012 (1797), p. 308], sean otras o la propia. Pero explícitamente personas son, según Kant, sólo aquellos sujetos

7 Véase: Guyer (2005); Timmermann (2008). Y la acertada crítica de Andrea Esser a la suposición teleológica de que una naturaleza racional universal del hombre sería el bien y opera en forma de un fin superior como presupuesto de la concepción kantiana véase: Esser (2004, p. 252).

8 En esa medida la posición de Kant en perspectiva teórica no es antropocéntrica (Mohr, 2007, p. 21), sino logocéntrica (Wood, 1998a, p. 189). 
cuyas "acciones son imputables" [Kant, 2012 (1797), p. 30], ${ }^{9}$ que, por tanto, pueden obrar en verdad de manera moralmente (o jurídicamente) responsable. La idea de que hay seres sin libertad respecto a los cuales pudiéramos estar obligados, obedece para Kant a una torpe confusión, a una "anfibología de los conceptos de la reflexión" [Kant, 2012 (1797), p. 308].

Con esto coincide el que la tercera fórmula del imperativo categórico, concebida por Kant como equivalente: "en consonancia con ello, todo ser racional tiene que obrar como si fuera por sus máximas siempre un miembro legislador en el reino universal de los fines" [Kant, 2012 (1797), p. 308] suponga que sólo miembros semejantes en el reino de los fines - es decir, en el ideal inteligible de un estado bien coordinado para fijación subjetiva de fines - son quienes poseen la facultad de darse leyes a sí mismos a partir de la razón pura práctica y quienes pueden seguir en sus acciones estas normas de manera permanente. En este sentido se considera de manera exclusiva la "idea de la dignidad de un ser racional que no obedece a ninguna otra ley que a la que da a la vez él mismo" [Kant, 1996 (1785) p. 199]. La ética kantiana se muestra exclusivamente, una vez más, como una ética del respeto mutuo, recíproco de seres racionales, que se respetan unos a otros como fines en sí mismos y, con ello, al mismo tiempo, como agentes racionales que se dan fines a sí mismos. El que Kant explique sistemática y recíprocamente, unos mediante los otros, los términos "dignidad", "finalidad en sí mismo", "persona" y "miembro legislador en el reino de los fines", corta el paso a la suposición de que la "fórmula del fin" del imperativo categórico puede ofrecer un espacio más amplio para la fundamentación de un concepto de dignidad que abarque a todos los hombres, que la tercera, la "fórmula del reino de los fines". ${ }^{10}$

Contra la interpretación aquí desarrollada no se podrá objetar, que Kant, particularmente en el contexto de sus escritos antropológicos e histórico-filosóficos [cf. Kant 2013 (1786), p. 177] emplea el concepto de humanidad regularmente también como un concepto histórico y/o biológico del género, que al comienzo del

9 Sobre la imputación en Kant véase: Kant (2005 [1788], p. 115); Kant (2012 [1797], p. 303). Ya de aquí se sigue que no es acertada la tesis según la cual el concepto de dignidad "no" podría "como concepto práctico de la razón [...] hacerse depender en su dignidad apriorística de la presencia efectiva de capacidades específicas" (Luf, 1998, p. 322).

10 Véase: Seelmann (2008, p. 77). La mutua sustitución de los conceptos "dignidad" y "fin en sí mismo" en la Fundamentación evidencia el carácter errático de la tesis de von der Pfordten según la cual, en el marco del desarrollo de la segunda fórmula del imperativo categórico Kant "ni explícita ni implícitamente" se refiere "a la dignidad del hombre o de la persona" (von der Pfordten, 2006, p. 504). 
escrito sobre la religión atribuye antropológicamente al hombre como ser genérico una "disposición [...] para su personalidad como ser racional y a la vez susceptible de que algo le sea imputado" [Kant, 1981 (1793), p. 43; cf. Wood, 2008, p. 88], que en su Antropología en sentido pragmático empiece el concepto de persona con una concepción psicológica de la conciencia del yo [Kant, 2014 (1798), § 1] o que en la Crítica del juicio piense la finalidad en sí misma de la persona también a partir de su capacidad de formar un ideal de belleza [Kant, 2012 b (1790), § 17], pues el uso que hace Kant de los conceptos de hombre o de humanidad en la fundamentación de los principios de su filosofía moral es otro bien distinto.

La ética kantiana fundamenta de este modo una moral exclusiva del respeto recíproco de las personas autónomas. La idea de la reciprocidad estructural y de la simetría de los deberes morales es constitutiva de ella. Dentro del limitado círculo de las personas moralmente capaces de acción, la ética kantiana procede en forma igualitaria e incluyente. El estatus de ser fin en sí mismo y portador de dignidad, le corresponde en igual medida (es decir, absoluta) a todas las personas suficientemente racionales en sentido práctico, es decir, que dispongan de "razón humana ordinaria" [cf. Kant, 1996 (1785), p. 243]. El estatus de persona es entonces un concepto límite (Schwellenbegriff), su lógica es binaria — se es persona completamente (y se tiene estatus moral) o no se es en absoluto, y dentro de este estatus no hay gradaciones meritocráticas, no hay aristócratas de la dignidad. Dado, finalmente, que la dignidad está unida exclusivamente sólo a la capacidad para el obrar moral autónomo y no a su ejercicio, este estatus tampoco se pierde —ni siquiera por una inmoralidad sistemática. Por tanto, se debe afirmar: la dignidad consiste para Kant en la capacidad actual para la autodeterminación racional (moral). Ella, y únicamente ella, define el estatus de "persona" o de "sujeto moral", y esta capacidad no la poseen todos los hombres.

¿Quién es, entonces, persona en sentido kantiano? Las exigencias son altas, en vista de la pretenciosa definición del concepto. Aun cuando no partamos, con Reinhard Brandt, de que la antropología de Kant, que parece poner en duda el que las mujeres, los africanos o los isleños del pacífico sur estén en condiciones de autodeterminarse según principios de la razón, tiene que exigir de su filosofía moral aceptar "una división de clases entre seres humanos en mayoría de edad y seres humanos en minoría de edad [...]" y dirigirse con el imperativo categórico sólo a los primeros (Brandt, 1999; 1994, p. 30. Críticamente se expresa también 
Louden, 2000, pp. 101, 177); ${ }^{11}$ aun cuando queramos, además, ocultar el hecho de que la psicología moral empírica alimenta dudas acerca de que la mayoría de los adultos alcance nunca aquel estadio posconvencional del desarrollo moral al que pertenece el imperativo categórico, siguen existiendo, en todo caso, seres humanos que bajo ninguna circunstancia pueden cumplir las condiciones kantianas con que se cualifica a las personas: niños, personas con discapacidades mentales, dementes o en permanente estado de coma. En el sentido de la ética de Kant, ellos son nopersonas ( $c f$. Wood, 1999, p. 147) respecto a las cuales podamos tener deberes morales. Este resultado no es un resultado marginal, contingente, de la ética kantiana, antes bien se sigue de las suposiciones arquitectónicas fundamentales de su filosofía moral y no se ve por ello afectado por la circunstancia de que estas suposiciones fundamentales obtenidas de los principios de la razón pura práctica también en la perspectiva de Kant "requieren de la antropología para su aplicación a los hombres" [Kant, 1996 (1785), p. 155]. ${ }^{12}$

A ello se añade que el problema se agudiza por el hecho de que de que a la ética kantiana le es propia una estructura dicotómica fundamental. Ésta se manifiesta en su insistencia permanente, enfatizada una vez más en la Metafísica de las costumbres, en que los seres naturales que no representan personas son meramente cosas, que quien no es fin en sí mismo autónomo posee únicamente valor instrumental, que todo, excepto criaturas racionales capaces de autonomía puede ser "usado también como medio" y posee sólo valor instrumental. "En el reino de los fines", dice Kant, "todo tiene o un precio o una dignidad" [Kant, 1996 (1785), p. 199], tertium non datur, y esto torna difícil, cuando no imposible, comprender la cuestión relativa al estatus moral de seres humanos no autónomos o no suficientemente autónomos en un sentido gradual, es decir, como un Más o un Menos en subjetividad moral o en derechos morales.

La interpretación desarrollada aquí de la filosofía moral kantiana no pretende originalidad alguna; en todo caso, en la discusión actual es compartida por la mayoría de los intérpretes. El presente artículo hace más bien la pregunta de cómo hay que proceder con este resultado.

11 Las delimitaciones y límites sistemáticos de un reconocimiento igual y amplio de todos los hombres en Kant y el Idealismo alemán los analiza Siep. En vista de este resultado Siep recomendó intentar una fundamentación última de moral, derecho y Estado a favor de una concepción de experiencias históricas y de mundos de vida teóricamente cimentadas (Siep, 2010).

12 "Una metafísica de las costumbres no puede fundamentarse en la antropología, pero puede, sin embargo, aplicarse a ella" (Kant, 2012 [1797], p. 21). 


\section{Un problema arquitectónico}

En este contexto resulta importante, en principio, el que la estructura ambivalente de la ética kantiana - fundamentación de una posición moral bastante fuerte y sólida (y por lo demás igualitaria) suficiente para seres humanos racionales, por un lado, exclusión de seres humanos no-autónomos del mundo moral en sentido estricto, por otro-, se vuelva a encontrar en los desarrollos ulteriores más importantes de la ética kantiana. Esto podría examinarse breve y ejemplarmente en la ética del discurso, en el constructivismo kantiano de Rawls y en planteamientos similares de la actual teoría kantiana del contrato.

Tras el linguistic turn se hizo evidente la pretensión de hacer desembocar el movimiento universalizador de pensamiento que acompañaba al imperativo categórico en el intento de una ampliación dialógica de la ética kantiana ( $c f$. Wellmer, 1986). La ética del discurso transitó este camino. Su idea rectora, la de que una norma es válida únicamente si puede encontrar consentimiento en el círculo de todos los afectados bajo las condiciones de la formación discursiva de la voluntad, puede pretender para sí el haber replanteado una intención esencial de Kant y haber reformulado la teoría moral de Kant con los medios de una teoría de la comunicación ( $c f$. Habermas, 1980, p. 9). "Usar" al otro "no meramente como medio, sino también al mismo tiempo como fin", equivale, como enfatiza Kant ya en la Crítica de la razón práctica a "no someterlo a un propósito que no sea posible según una ley que pudiera derivar de la voluntad del sujeto pasivo mismo" [Kant, 2005 (1788), p. 104; Rawls, 2002, p, 259].

Así como Kant limita la esfera de los objetos de los deberes morales a personas - es decir, a seres que "bien sea solos o al menos juntamente con otros [...]" "se" dan "sí mismos" las leyes morales bajo las cuales se encuentran [Kant, 2012 (1797), p. 30]—, también, según Habermas, en la ética del discurso esa esfera se encuentra limitada fundamentalmente a aquellos seres que cumplen las condiciones del obrar normativamente imputable (es decir, son personas, en la definición de Kant) y pueden asumir los roles de los participantes en discursos prácticos (Habermas, 1980, p. 517; 1983, p, 89). Como en Kant, también en la ética del discurso sólo es ciudadano del mundo de la moral aquel que puede cooperar en la fundamentación de sus normas. En esa medida, también en Habermas el sentido de las pretensiones normativas de validez descansa en una relación igualitaria, recíproca, entre personas (Habermas, 1980, p. 518) que participan en 
argumentaciones y pueden motivarse por medio de razones. Y tales no son, una vez más, todos los seres humanos y ningún ser humano en todos los momentos del tiempo de su existencia.

El estatus moral de quien es incapaz de discurso no puede determinarse por principio con los medios de la ética del discurso; en todo caso, él surge, al igual que el estatus moral de la naturaleza no-humana, como un concepto límite. ${ }^{13} \mathrm{El}$ estatus moral de las personas incapaces de discurso no puede integrarse en el programa de la ética del discurso. Tales personas no pueden participar por sí mismas en el discurso ni participar en la fundamentación de normas morales; en todo caso, sus intereses pueden ser representados por otros. A la ética del discurso y a la teoría kantiana les es además común el que el obrar propio se debe legitimar en y frente a la razón individual tanto del otro concreto como del otro generalizado y esta legitimación puede tener lugar sólo en tanto este otro es suficientemente racional.

Este elemento de reciprocidad en los fundamentos de la moral caracteriza igualmente la reformulación constructivista, del orden de una teoría contractualista, del principio kantiano, llevada a cabo por John Rawls quien, en su Historia de la filosofia moral (Rawls, 2002) remonta de manera expresa su propio "constructivismo kantiano", una vez más, al razonamiento de la Fundamentación de la metafísica de las costumbres. Rawls explicita, como se sabe (desde su obra Teoría de la justicia), principios para la justicia de las instituciones sociales con ayuda de una idea de la teoría de juegos de inspiración kantiana, que obtiene la hipótesis acerca de la imparcialidad y universabilidad de los principios encontrados de la estructura de la situación construida de la decisión. Él pregunta por los principios de la justicia social que pudieran elegir individuos en un ficticio estado original, en el que los afectados poseen, ciertamente, conocimientos generales, pero no disponen de un saber acerca de qué intereses concretos o propiedades, qué estatus social, etc., tendrán en la sociedad así definida. Los participantes de la original position rawlsiana se ven obligados de este modo en el proceso de fundamentación de normas a trascender sus intereses propios y a asumir la perspectiva de otros intereses posibles.

También en Rawls se repite en este caso la restricción kantiana de la esfera de objetos de las normas fundadas de esta manera; de nuevo, como en Habermas, se refuerza la idea kantiana de que únicamente aquel que es destinatario de la moral

13 La teoría del discurso es, lo mismo que la ética kantiana, logocentrista, no antropocentrista, como cree Habermas. Confrontar: Habermas (1980, p. 514). 
y, al mismo tiempo, objeto de sus deberes, puede participar en el proceso de la fundamentación de normas. "Igual justicia", según la reformulación kantiana de Rawls, "debe observarse sólo frente a aquellos que están en condiciones de participar en la posición original", por ende, sólo "personas morales" (Rawls, 1993, § 77), si bien Rawls admite explícitamente dificultades particulares relacionadas con la fundamentación del estatus moral de personas que "han perdido su personalidad moral en forma más o menos duradera" (Rawls, 1993, p, 553). No parece ser ninguna casualidad que esta idea no pertenezca a aquellas a las que Rawls ha sometido a una revisión (aun cuando el planteamiento rawlsiano sería con mucho el más apropiado, para, con sólo pocas ampliaciones teóricas, derivar normas del trato con seres humanos no autónomos). De manera enteramente semejante subyace la restricción kantiana del reino de la moral a las relaciones igualitarias, recíprocas, entre personas que se motivan por medio de razones, al contractualismo ético de Thomas Scanlon, según el cual un principio moral sólo puede legitimarse si no puede ser rechazado de manera razonable por ninguno de los distintos individuos implicados (Scanlon, 1982; 1998, pp.191, 229).

Este breve esbozo debería haber hecho plausible que la pregunta por el estatus moral de seres humanos no autónomos es un problema fundamental no sólo de la ética de Kant, sino también de los desarrollos ulteriores de la ética kantiana. Se trata de un problema de la arquitectura de la teoría.

\section{Consecuencias}

Si se observa este resultado desde afuera — por ejemplo desde la perspectiva de la crítica a la moral de tipo nietzscheano, tal como se la encuentra en Foucault-, se abre entonces la posibilidad de describir esta exclusión de seres no racionales del estrecho círculo de la moral como una parte de la historia de las exclusiones a través de la cual se define ex negativo la cultura occidental. En el marco de una arqueología de la razón moderna, como la emprendió Foucault en su estudio sobre Locura y sociedad, se podría caracterizar la filosofía práctica de Kant como un acto fundacional de la autoconstitución de la ética racional moderna mediante su exclusión continua (y dominación) de lo "otro" de ella, es decir, la naturaleza no racional. Nada distinto cree Theodor W. Adorno, cuando en su lección sobre Problemas de la filosofía moral afirma que "la moral kantiana [...] no es propiamente otra cosa que dominio" (Adorno, 1963, p. 157; $c f$. Arendt, 1991, p. 142; Bayertz, 1995). 
Las consecuencias deberían, sin embargo, ser otras. En primer lugar: el propósito fundamental de Kant, según el cual las personas tienen derecho a una forma particular de respeto, que no corresponde a otros seres, es obligatoria desde el punto de vista normativo.

En segundo lugar: una ética que enfatiza la posición particular de las personas capaces de autodeterminación y en consecuencia atribuye significado moral a determinadas cualidades, tiene que proceder necesariamente de manera discriminatoria y excluir en principio todos los seres que no exhiben estas cualidades. Este es el precio que tenemos que pagar cuando, como Kant, le atribuimos a la autonomía un significado normativo tan elevado.

En tercer lugar: el principio del respeto a las personas ha transitado de la filosofía moral kantiana al programa genético del estado de derecho liberal. Este proceso se ha propiciado - a este respecto de manera inmediata - gracias a la propia teoría del derecho de Kant, y se reforzó particularmente por la primera ola de la recepción de la filosofía kantiana del derecho entre 1790 y 1830, así como por la nueva formulación de la filosofía liberal del derecho sobre bases kantianas, tal como se presentó desde los años 70 del siglo pasado, sobre todo en los países anglosajones. El contenido del concepto del principio del respeto a una persona qua persona se ha ampliado al respeto por la persona jurídica y sus derechos a la libertad; se exige no sólo respeto a la autonomía moral del sujeto, sino también, dejar a cargo del individuo singular la propia interpretación de la vida y entender su derecho a la autodeterminación como un derecho a la soberanía que le asegura al individuo singular, al menos, prima facie, una prerrogativa sobre los intereses de la comunidad. Este kantianism in action no puede ser eliminado del entramado de nuestras convicciones normativas institucionalizadas.

Cuarto: precisamente a causa del carácter de irrenunciable que tiene el modelo kantiano de legitimación para los fundamentos normativos del estado de derecho liberal, debería tomarse en serio el grave problema del estatus moral de seres humanos no suficientemente autónomos, que Kant no se propuso conscientemente (Tugendhat, 1993, p. 188), en lugar de encubrirlo con préstamos del repertorio aristotélico y tomista. Podría ponerse en duda el poder de convicción del planteamiento kantiano en su conjunto si esta cuestión no condujera a un tratamiento adecuado. Bajo este aspecto resulta sorprendente que sólo en las dos últimas décadas este problema haya llamado fuertemente la atención en la investigación kantiana. 


\section{Alternativas}

¿Cómo podemos lidiar en el terreno de la teoría moral kantiana con el resultado obtenido hasta ahora, según el cual la fundamentación moral kantiana del respeto a las personas deja indeterminado, en el mejor de los casos, el derecho a la dignidad de la consideración de las "no-personas" y tiene, a la postre, que negarlo? Pueden describirse cuatro opciones, en orden ascendente, según su cercanía a los propósitos de Kant.

(1). Es necesario recordar primero el propio tratamiento que da Kant del problema. En la Metafisica de las costumbres esbozó la estructura de una protección normativa al menos indirecta para seres naturales no racionales tomando como ejemplo el trato con los animales. ${ }^{14}$ Dicho tratamiento se acoge al programa de concebir supuestos deberes frente a seres no-racionales como deberes frente a nosotros mismo. Por eso, no tratar cruelmente a los animales, no es para Kant un deber respecto a los animales, sino deber del hombre para consigo mismo en vista a los animales. Este deber reside en el hecho de que, por la brutalidad que conlleva la tortura animal, "se destruye paulatinamente una predisposición natural muy útil a la moralidad en relación con los demás hombres" [Kant, 2012 (1797), p. 310]. Este nexo formulado en el sentido de una ética de la virtud es de índole psicológico-moral, es decir, mediado empíricamente y en cuanto tal contingente, si bien puede apoyarse en una cierta plausibilidad.

En una reconstrucción inmanente de la posición kantiana el tratamiento de los niños, las personas seniles, los dementes, los enfermos mentales o en coma podría medirse partiendo de lo que nos debemos a nosotros mismos, no a ellos, y a la "idea de la humanidad en nosotros". El nexo empírico necesario podría reconstruirse. Al menos parece hablar a favor de la tesis el que una moral del respeto recíproco, mutuo, entre personas autónomas queda inacabado y no se puede estabilizar, si ella no puede justificar una protección fuerte para nuestros semejantes más débiles. Nada trivial sería su protección a través de deberes indirectos, es decir, mediante un simple reflejo de la protección, pues tales deberes tienden a la protección de normas, es decir, a la estabilización de la fuerza de integración de un orden de normas que descansa en el reconocimiento recíproco de personas racionales que

14 Para una tesis, formulada de manera diferenciada, sobre el carácter no vinculable de la ética kantiana con el concepto de los deberes frente a los animales, véase: Skidmore (2001). 
alguna vez fueron ellas mismas niños y que son conscientes de la vulnerabilidad y fugacidad de sus capacidades racionales. Por eso parece plausible la tesis de que no podemos tratarnos mutuamente con respeto si tratamos sin respeto a nuestros niños, y a nuestros semejantes dementes y mentalmente enfermos. A pesar de esta opción persiste aún la afrenta de que se les niegue a los seres humanos no considerados personas la condición de miembros de la comunidad moral, mientras no se abandone, al menos parcialmente, el contexto kantiano de fundamentación.

(2). Según Kant, el estatus moral de la persona (su dignidad) reside en su capacidad actual, es decir, fundamentalmente presente, para la autodeterminación racional (moral). Si se quiere permanecer en el edificio teórico de Kant, pero, no obstante, intentar vencer el umbral del tiempo que rodea a esta demanda de actualización, quedan dos posibilidades. Por un lado, la autonomía puede seguir actuando, es decir, una persona puede relacionarse prospectivamente respecto de una posible pérdida posterior de su autonomía y determinar cómo se debe proceder con ella en este caso futuro. Un respeto de la persona kantianamente entendido nos obliga a acatar tales actos expresos de autodeterminación anticipadora. ${ }^{15} \mathrm{Algo}$ similar podemos suponer también en relación con la presunta voluntad de un sujeto autónomo en el pasado, en el caso de que podamos comprobar tal voluntad.

Por el otro lado del espectro, en relación con el trato con niños pequeños, es decir, 'aún no-personas' en el sentido kantiano, se puede intentar obtener la legitimación de su tratamiento a partir de la suposición fundada contrafácticamente de un consenso posible con ellos, es decir, preguntándose si existen razones para suponer que ellos podrán (podrían) aprobar en lo sucesivo lo que hacemos con ellos. En todo caso, los niños pueden ser representados de esta manera en el proceso de la deliberación moral. Thomas Hill (2000; nota 18) y Jürgen Habermas (2005, pp. 78, 91, 149) argumentan de esta manera y ya el tratamiento que hace Kant del derecho paterno, según el cual, el deber de los padres en vista a los intereses de sus hijos debe originarse del hecho de que ellos "sin su consentimiento" los "han puesto en el mundo y traído a él arbitrariamente" [Kant, 2012 (1797), p 102], parece abrirse al menos a una interpretación que recurre a la posibilidad fundada del consenso hipotético o que se espera ex post de los afectados.

Para una solución del problema con medios kantianos este planteamiento parece bastante prometedor. El ámbito de la influencia excluyente de la ética kantiana se reduce de este modo de manera considerable, aunque no completamente. "Por

15 Para un desarrollo sistemático de este contexto, véase: Quante (2002, p. 268; 2010, cap. IX). 
fuera" quedan seres humanos que no fueron antes autónomos ni lo serán jamás, como los enfermos mentales de nacimiento y personas que han perdido su autonomía, sin dejarnos pistas para el modo de proceder con ellos. Los fundamentos éticos de su tratamiento tendrían que buscarse también en el marco de esta ampliación fuera del marco de la ética kantiana. En esa medida, la moral racional kantiana se muestra necesitada de complementación.

(3). Una tercera vía consiste en emprender correcciones graduales a la teoría kantiana, es decir, intentar en piecemeal engineering teórico la reparación del barco kantiano en mar abierto. Allen Wood ha llevado a cabo tal intento, apoyado por Onora O’Neill (1996, cap. 4; 1998). Él proponía abandonar el 'principio de personificación' de la ética kantiana, según el cual, "la humanidad", entendida como la capacidad de autodeterminación, sólo debe ser respetada en la persona concreta que la encarna realmente.

Wood aduce buenas razones para su propuesta, que discurre hacia una reformulación teorético-valorativa de Kant. La teoría moral kantiana de la Fundamentación de la metafísica de las costumbres y de la Crítica de la razón práctica impone, como se ha expuesto, la conclusión de que los niños pequeños, las personas con enfermedades mentales, las personas seniles, dementes o en estado de coma, no son personas en el sentido kantiano del concepto, pero nos resistimos a atribuir a Kant la conclusión de calificarlos como meras cosas. Podemos inferir de su doctrina del derecho que, al menos en lo que respeta a los niños, no era eso realmente lo que quería, aun cuando no es claro lo que él pretendía [Kant, 2012 (1797), p. 101].

La renuncia al 'principio de la personificación' abriría en verdad el camino para mantener la caracterización kantiana de la naturaleza racional y respetarla de manera omniabarcante, es decir, in abstracto, respetarla, por lo tanto, como razón latente o en crecimiento en los niños, como recuperable en enfermos y víctimas de accidente, como desaparecida o existente en forma fragmentaria en personas dementes (o incluso en otros mamíferos). En esta interpretación, existirían deberes respecto a estos seres humanos y respecto a animales, y podrían y tendrían que ser calificados al menos en principio como sujetos morales, aunque con ello no se hubiera acordado qué deberes morales específicos tendríamos in concreto respecto de ellos. De esta manara puede hacerse plausible el que el estatus moral de seres humanos que "no son personas en sentido estricto" y necesitan por ello de la 
representación de otros en la percepción de sus intereses y también con miras a ser portadores de "dignidad", no debe, en todo caso, caer cualitativamente por detrás del estatus moral de las personas en sentido estricto (Wood, 2008, p. 97, 100). ${ }^{16}$

Con la renuncia al 'principio de personificación' se abandona la restricción consistente en que sólo exclusivamente las capacidades para la autodeterminación, efectivamente existentes, califican a un ser como sujeto moral según principios de una moral posconvencional. Una ocasión para los kantianos de proceder de manera generosa con esta exigencia de actualización la ofrece ya la circunstancia de que también las personas (humanas) autónomas regularmente duermen. Wood y O’Neill enfatizan el punto de vista de que el respeto a la razón en la naturaleza humana implica al mismo tiempo la conciencia de la fragilidad, la contingencia y la dependencia en el desarrollo de esta razón. Esta idea tiene una especial plausibilidad en relación con nuestros deberes morales hacia los niños, precisamente también en vista de su desarrollo [Kant, 2012 (1797), p. 101]. Una vez más se confirma que una ética del respeto de la naturaleza racional no parece viable sin tal ampliación; en esa medida, esta reflexión es cercana a la figura de argumentación central en Kant, según la cual las máximas de la acción deben examinarse atendiendo a si expresan el respeto a la dignidad de los seres autónomos. Además de ello, este desplazamiento teórico parece encajar bien con la conciencia de los procesos de desarrollo tanto en relación con el género humano como con cada ser humano particular, tal como Kant los aborda en sus escritos sobre filosofía de la historia y sobre pedagogía. Con dicho desplazamiento se quebraría, al mismo tiempo, el dualismo problemático que, además de personas en todo el sentido de la palabra, pretende reconocer únicamente cosas.

No obstante, es necesario poner en duda el que este resultado pueda lograrse sin fisuras en el camino de la simple interpretación o de la crítica inmanente de la ética kantiana. Ello es así, porque, en primer lugar, con el abandono del 'principio de personificación' se rompe el nexo de la referencia recíproca de las diferentes formas del imperativo categórico y, en segundo lugar, se tiene que abandonar la idea, tan importante para Kant, de que ciudadano del mundo moral sólo puede ser aquel que puede cooperar en la fundamentación de sus normas. El deber moral, insiste Kant, reside

16 Este autor es quien enfatiza al mismo tiempo que el argumento no se puede extender a embriones y fetos. Para esto último, confrontar: Siep (2009). 
en la relación de los seres racionales unos con otros, en la cual la voluntad de un ser racional tiene que ser considerada siempre a la vez como legisladora, porque, de otro modo, el ser racional no podría pensarlos como fin en sí mismo [Kant, 1996 (1785), p. 199]

- el concepto de persona y su estatus moral penden en Kant de manera inseparable de su capacidad para la autonomía moral. En vista de ello, la reconstrucción del barco kantiano, propuesta por Allen Wood y Onora O'Neill, difícilmente se podrá llevar a cabo en mar abierto.

(4). Dentro de la cuarta estrategia de distanciamiento, la de la decisión, se podría incluir la variante de Ernst Tugendhat de una moral de la prohibición de la instrumentalización, kantianamente inspirada, y del respeto universal. Tugendhat pretende sustituir el "anticoncepto" [Unbegriff] del "fin en sí mismo" por la idea de que es sencillamente el acto del respeto del otro como sujeto jurídico (y moral) (y como portador de fines subjetivos), el que le confiere a éste dignidad y valor. La condición de fin en sí mismo de la persona no debe suponerse, por tanto, como un acontecimiento ontológico dependiente de determinadas propiedades (Tugendhat, 1993, p. 145). Aunque también Tugendhat parte de que en una moral universalista de tipo kantiano, los sujetos y objetos de la moral se componen en sí sólo de seres responsables y capaces de cooperación, es decir, de la totalidad de aquellos que "pueden hacer exigencias unos a otros" (Tugendhat, 1993, p. 187), soluciona el problema de un plumazo. Según Tugendhat, incluimos seres no-responsables o nocapaces de cooperación en la (en 'nuestra') moral universalista por cuanto que los consideramos como pertenecientes a nuestra comunidad. La pregunta por el estatus moral de un ser se decide por consiguiente para él simplemente según el "lema 'él es uno de nosotros"' (Tugendhat, 1993, p. 195), con lo que esta decisión podría seguir a un amplio espectro de normas, motivos y necesidades. Tugendhat mismo considera el nacimiento de un ser humano como aquella cesura que lo convierte en objeto válido de la obligación (Tugendhat, 1993, p. 194): los niños nacidos pertenecen sencillamente 'a nosotros'. Es necesario, sin embargo, preguntar quién es ese 'nosotros', quién habla por este 'nosotros', cómo actúa este 'nosotros' y si no hay que representarse más bien la comunidad de la comunicación antes como una diversidad plural en la que algunas communities querrán quizá seguir otros principios. ¿Podrá ser la confianza de Tugendhat en el "lema "él es uno de nosotros"” algo más que una afirmación estadística sobre la distribución normal de intuiciones morales del mundo de la vida? El resultado de esta estrategia decisionista recuerda al menos que, en vista del potencial de exclusión del concepto de persona de la tradición ética kantiana, el mejor camino podría ser el de recuperar la necesidad 
filosófica de una legitimación y fundación, de una fundamentación fuerte o de una fundamentación última en las cuestiones del 'estatus moral'. También a partir de este resultado se puede una vez más, empero, aprender ex negativo que la ética kantiana, pese a la ampliación sistemática de su potencial de argumentación, sólo de manera muy limitada resulta apropiada para fundamentar deberes morales de seres humanos no (suficientemente) racionales.

\section{Referencias}

Adorno, T. W. (1996). Probleme der Moralphilosophie. Nachgelassenen Schriften, Bd. 4/10. Frankfurt a. M.: Suhrkamp.

Arendt, H. (1991). Vita Activa oder Vom tätigen Leben. München und Zürich: Piper.

Bayertz, K. (1995). Die Idee der Menschenwürde: Probleme und Paradoxien. ARSP: Archiv für Rechts-und Sozialphilosophie/Archives for Philosophy of Law and Social Philosophy, 81(4), 465-481.

Brandt, R. (1994). Ausgewählte Probleme der Kantischen Anthropologie. En Der ganze Mensch: Anthropologie und Literatur im 18. Jahrhundert (pp. 14-32). Stuttgart: JB Metzler.

Brandt, R. (1999). Kritischer Kommentar zu Kants ,, Anthropologie in pragmatischer Hinsicht “ (1798). Hamburg: Felix Meiner.

Cohen, H. (1877). Kants Begründung der Ethik. Berlin: Harrwitz und Gossmann.

Dworkin, R. (1984). Rights as Trumps. En J. Waldron (Ed.), Theories of Rights (pp. 153-167). Oxford: Oxford University Press.

Dworkin, R. (1985). Liberalism. En A Matter of Principle (pp. 181-204). Oxford: Clarendon Press.

Esser, A. (2004). Eine Ethik für Endliche. Kants Tugendlehre in der Gegenwart. Stuttgart: Frommann-Holzboog.

Geismann, G. (2004). Kant und das vermeinte Recht des Embryos. Kant Studien, 95, 443-469.

Guyer, P. (2005). Ends of Reason and Ends of Nature. The Place of Teleology in Kant's Ethics. En Kant's System of Nature and Freedom. Selected Essays (pp. 169-197). Oxford, New York: Oxford University Press.

Habermas, J. (1980). Replik auf Einwände. In Vorstudien und Ergänzungen zur Theorie des kommunikativen Handelns (pp. 475-570). Frankfurt a. M.: Suhrkamp.

Habermas, J. (2005). Die Zukunft der menschlichen Natur. Auf dem Weg zu einer liberalen Eugenik? Frankfurt a. M.: Suhrkamp.

Herman, B. (1993). The Practice of Moral Judgement. Cambridge: Cambridge University Press.

Hill, T. E. (2000). Respect, Pluralism and Justice. Kantian Perspectives. Oxford, New York: Oxford University Press.

Horn, C. (2004). Die Menschheit als Objektiver Zweck. Kants Selbstzweckformel des 
kategorischen Imperativs. En K. Ameriks \& D. Sturma (Eds.), Kants Ethik (pp. 195-212). Paderborn: Mentis.

Kant, I. [1981 (1793)]. La religión dentro de los límites de la mera razón (F. Martínez Marzoa, Trad.). Madrid: Alianza.

Kant, I. [1996 (1785)]. Fundamentación de la metafísica de las costumbres (J. Mardomingo, Trad). Barcelona: Ariel.

Kant, I. [2002 (1795)]. Sobre la paz perpetua (J. Abellán, Trad.). Madrid: Alianza.

Kant, I. [2005 (1788)]. Crítica de la razón práctica (D. M. Granja Castro, Trad.). México: Fondo de Cultura Económica.

Kant, I. [2012a (1797)]. La metafísica de las costumbres (A. Cortina \& J. Conill, Trad.). Madrid: Tecnos.

Kant, I. [2012b (1790)]. Crítica del discernimiento (o de la facultad de juzgar) (R. R. Aramayo \& S. Mas, Trad.). Madrid: Alianza.

Kant, I. [2013 (1786)]. Probable inicio de la historia humana. (R. R. Aramayo, Trad.). Madrid: Alianza.

Kant, I. [2014 (1798)]. Antropología en sentido pragmático (D. M. Granja Castro, G. Leyva \&P. Storandt, Trad.). México: Fondo de Cultura Económica.

Korsgaard, C. M. (1996). Creating the Kingdom of Ends. Cambridge, New York: Cambridge University Press.

Korsgaard, C. M. (2005). Fellow Creatures, Kantian Ethics and Our Duties to Animals. En G. B. Peterson (Ed.), The Tanner Lectures on Human Values (Volume 25/26). Salt Lake City: http://www.tannerlectures.utah.edu/lectures/documents/volume25/korsgaard_2005.pdf

Louden, R. B. (2000). Kant's Impure Ethics. From Rational Beings to Human Beings. New York/Oxford: Oxford University Press.

Luf, G. (1998). Menschenwürde als Rechtsbegriff. Überlegungen zum Kant-Verständnis. En R. Zazcyk, M. Köhler \& M. Kahlo (Eds.), Festschrift für Ernst Amadeus Wolff zum 70. Geburtstag (pp. 307-323). Berlin, Heidelberg, New York: Springer.

Mohr, G. (2007). Ein Wert, der keinen Preis hat. Philosophiegeschichtliche Grundlagen der Menschenwürde bei Fichte und Kant. En H.J. Sandkühler (Ed.), Menschenwürde, Philosophische, theologische und juristische Analysen (pp. 13-39). Frankfurt a. M., New York: Lang.

O’Neill, O. (1975). Acting on Principle. An Essay in Kantian Ethics. Cambridge, New York: Cambridge University Press.

O’Neill, O. (1989). Constructions of reason: Explorations of Kant's practical philosophy. Cambridge, New York: Cambridge University Press.

O`Neill, O. (1996). Tugend und Gerechtigkeit: eine konstruktive Darstellung des praktischen Denkens. Berlin: Akademie-Verlag.

O’Neill, O. (1998). Kant on Duties Regarding Nonrational Nature, Proceedings of the Aristotelian Society, Supplementary Volume, 72(1), 211-228. 
Pogge, T. W. (1989). The Categorical Imperative. En O. Höffe(Ed.), Grundlegung zur Metaphysik der Sitten (pp. 172-193). Frankfurt a. M.: Suhrkamp.

Quante, M. (2002). Personales Leben und menschlicher Tod. Personale Identität als Prinzip der biomedizinischen Ethik. Frankfurt a. M.: Suhrkamp.

Quante, M. (2007). Person. Berlin: Walter de Gruyter.

Rawls, J. (1993). Political Liberalism. New York: Columbia University Press.

Rawls, J. (2002). Geschichte der Moralphilosophie. Frankfurt a. M.: Suhrkamp.

Ricken, F. (1989). Homo noumenon und homo phaenomenon. En O. Höffe (Ed.), Grundlegung zur Metaphysik der Sitten. Ein kooperativer Kommentar (pp. 234-252). Frankfurt a. M.: Vittorio Klostermann.

Scanlon, T. M. (1982). Contractualism and Utilitarianism. En A. Sen \& B. Williams (Ed.), Utilitarianism and Beyond (pp.103-128). Cambridge: Cambridge University Press.

Scanlon, T. M. (1998). What We Owe to Each Other $\left(4^{\text {th }}\right.$ ed). Cambridge, MA: Harvard University Press.

Schönecker, D \& Wood, A. W. (2007). Kants Grundlegung zur Metaphysik der Sitten. Ein einführender Kommentar. Paderborn: UTB.

Seelmann, K. (2008). Menschenwürde und die zweite und dritte Formel des Kategorischen Imperativs. Kantischer Befund und aktuelle Funktion. En G. Brudermüller \& K. Seelmann, (Eds.), Menschenwürde. Begründung, Konturen, Geschichte (pp.67-77). Würzburg: Königshausen \& Neumann.

Siep, L. (2009). Das Menschenwürdeargument in der ethischen Debatte über die Stammzellforschung. En K. Hilpert (Ed.), Forschung contra Lebensschutz? Der Streit um die Stammzellforschung (pp. 182-199). Freiburg, Basel, Wien: Herder.

Siep, L. (2010). Toleranz und Anerkennung bei Kant und im Deutschen Idealismus. ders., Aktualität und Grenzen der praktischen Philosophie Hegels. Aufsätze (pp. 77-91). München: Wilhelm Fink.

Skidmore, J. (2001). Duties to animals: The failure of Kant's moral theory. The Journal of Value Inquiry, 35(4), 541-559.

Sturma, D. (2001). Person und Philosophie der Person. En D. Sturma, D. (Ed.), Person. Philosophiegeschichte - Theoretische Philosophie - Praktische Philosophie (pp. 11-22). Paderborn: Mentis.

Timmermann, J. (2006). Value without Regress: Kant's 'Formula of Humanity' Revisited. European Journal of Philosophy 14(1), 69-93.

Timmermann, J. (2008). Limiting Freedom: On the Free Choice of Ends in Kantian Moral Philosophy. En V. Rohden, R.R. Terra, D.A. de Almeida \& M. Ruffing (Hrsg. im Auftrag der Kant-Gesellschaft), Recht und Frieden in der Philosophie Kants. Akten des X. Internationalen Kant-Kongresses (pp. 427-437). Berlin, New York: De Gruyter.

Tugendhat, E. (1993). Vorlesungen über Ethik. Frankfurt a. M.: Suhrkamp.

Von der Pforten, D. (2006). Zur Würde des Menschen bei Kant. Jahrbuch für Recht und Ethik, $14,501-517$. 
Walker, R. C. S. (1989). Achtung in the Grundlegung. En O. Höffe (Ed.), Grundlegung zur Metaphysik der Sitten. Ein kooperativer Kommentar (pp. 97-116). Frankfurt a. M.: Vittorio Klostermann.

Wellmer, A. (1986). Ethik und Dialog. Elemente des moralischen Urteils bei Kant und in der Diskursethik. Frankfurt a. M.: Suhrkamp.

Wood, A. W. (1998): Humanity As End in Itself. In P. Guyer (Ed.), Kant's Groundwork of the Metaphysik of Morals. Critical Essays (pp. 165-187). Lanham, Boulder, New York.

Wood, A. W. (1998a): Kant on Duties Regarding Nonrational Nature. En Proceedings of the Aristotelian Society, Supplementary Volume, 72(1), 189-210.

Wood, A. W. (1999): Kant's Ethical Thought. New York, Melbourne: Cambridge University Press.

Wood, A. W. (2002): The Final Form of Kant's Practical Philosophy. In M. Timmons (Ed.), Kant's Metaphysics of Morals. Interpretative Essays, Oxford, 1-22.

Wood, A. W. (2008): Kantian Ethics. Cambridge, New York, Melbourne: Cambridge University Press. 